\title{
NATURALEZA JURIDICA DE LAS EMPRESAS MULTINACIONALES
}

Una multitudinaria reunión de abogados de todos los paises de América, celebrada el pasado mes de agosto en Río de Janeiro, resolvió recomendar la adopción, "como uno de los temas centrales a ser tratados por la próxima Conferencia, de una definción jurídica de sociedades multinacionales, sobre la capacidad de decisión y sobre los aspectos jurídicos vinculados con las sociedades multinacionales, incluyendo la regulación jurídica de las mismas en los países en que operan"' (1).

El sentido de oportunidad de esta proposición se comprende solamente en la medida en que puede preverse que la naturaleza económica y jurídica de las empresas multinacionales habrá cambiado con respecto a lo que es hoy en día cuando se reúna nuevamente la Conferencia dentro de un par de años. Pero ese sentido parece menos claro si la definición jurídica de este fenómeno preocupa ahora, en cuyo caso no se justificaría postergar el intento, aun cuando dicha preocupación fuera meramente académica.

Sin embargo, la importancia de las empresas multinacionales no es, como todo el mundo sabe, un tema académico. En este mismo momento, todos los países de América -desde Estados Unidos hasta Argentina- están estableciendo, acaban de establecer, o están programando, instrumentos legales de todo tipo, nivel y alcance para regular la actividad de las empresas multinacionales. Casi todos los organismos internacionales -el ECOSOC, la UNCTAD, Ia OIT, Ia asamblea general de las Naciones Unidas- están proponiendo líneas de acción internacional en la materia (2) y

1. XVIII Conferencia de la Federación Interamericana de Abogados, Resolución Cj-6, Comité XI - Sección A. 2. Véase el reciente informe de Naciones Unidas, Multinational Corporations in World Development, New York, 1973, p. 106 y siguientes. también los organismos regionales de integración económica, especialmente los latinoamericanos, otorgan prioridad a la adopción de medidas, ya sea para controlar, ya sea para promover, distintos tipos de empresas multinacionales (3).

Es alarmante que mientras este movimiento se está llevando a cabo, los juristas todavia manifiesten su ignorancia frente al fenómeno que se trata de regular. ¿Qué garantía, entonces, tendrán los sectores interesados y en primer lugar los gobiernos, sobre la adecuación y la seriedad de los instrumentos legales e institucionales que se diseñen?

La recomendación de la Conferencia de Abogados revela, entre otras cosas, que persiste la confusión conceptual sobre un tema que si bien es nuevo, y polifacético, ya está suficientemente experimentado; y aunque así no fuera, difícilmente puede resistir la capacidad descriptiva de una ciencia habituada a no dejar lagunas en la realidad social, como es el Derecho.

En el caso de los juristas latinoamericanos, la confusión puede explicarse, quizás, porque los problemas que vienen surgiendo en las relaciones económicas, sociales e internacionales de las últimas décadas siguen enfocándose en buena medida con las categorias obsoletas del Derecho Romano, como si fuera posible pensar juridicamente en 1973 con los principios y reglas de juego aplicables a las sociedades pastoriles de la antigüedad.

Las dificultades de los juristas para representar adecuadamente al fenómeno de las empresas multinacio-

3. El Grupo Andino ha dictado dos importantes Decisiones al respecto, la 24 y la 46 , que están actualmente en distintos grados de implementación. En el seno de la ALALC también se han producido recientemente importantes trabajos dentro del Plan de Acción establecido por la decisión 262 (IX). 
nales, igualmente que a otras realidades de nuestra época, persistirán mientras no se empleen las técnicas y razonamientos del derecho económico, es decir, mientras dichas realidades no se enfoquen en una perspectiva interdisciplinaria, que recurra a otros métodos que los puramente jurídicos, permita ubicar a los problemas como parte del proceso de cambio de los sistemas sociales y acepte, en consecuencia el carácter eminentemente dinámico y fluido de sus categorías conceptuales.

Las breves reflexiones que siguen tienen el propósito de contribuir a clarificar las principales ideas en torno al concepto juridico de empresa multinacional, ubicándolo en la perspectiva de las relaciones económicas internacionales contemporáneas (4).

\section{Cambios en las relaciones internacionales}

A partir de la Segunda Guerra Mundial, las relaciones económicas internacionales recibieron el impacto de varios procesos convergentes y en alguna medida contradictorios:

- La internacionalización masiva de los sistemas de producción, impulsada por factores políticos e institucionales - la liberación progresiva de los movimientos de personas, mercaderias y capitales- y por gigantescos avances de la tecnología, especialmente en materia de transportes y comunicaciones. Eliminados de esta manera muchos obstáculos que separaban antes a los países, las transacciones económicas internacionales aumentaron su volumen y cambiaron su naturaleza.

--La emergencia de los llamados nacionalismos económicos, especialmente en los países que comenzaron a denominarse "subdesarrollados" al tomarse conciencia de las brechas de nivel económico que los separaban de los paises industrializados. Los medios de expresión de este feriómeno ya estaban creados desde la crisis económica de 1930, frente a la cual los Estados debieron aprender, más allá de sus ideologías, a manejar politicas y mecanismos de intervencionismo y planificación. Más tarde, la capacidad de control estatal sobre las economías fue puesta al ser-

4. El tratamiento que se realiza a continuación está basaclo en varios trabajos del autor, y especialmente en "Empresas multinacionales latinoamericanas; la perspectiva del derecho económico", Fondo de Cultura Económica, México, 1973. vicio de objetivos más amplios, que pueden resumirse en la pretensión de consolidar y aumentar la autonomía nacional frente al sistema internacional, evitando la pérdida de capacidad de decisión generalmente calificada como dependencia externa.

- La formación de nuevos espacios económicos regionales, a través de esquemas de cooperación e integración económica entre Estados independientes que buscan poner en común sus mercados, estrechos ante la perspectiva de la competencia internacional, y sus recursos, escasos para realizar determinadas actividades consideradas necesarias por su significación económica o social.

Este conjunto de cambios y procesos ha afectado una serie de supuestos y reglas del juego sobre los que se llevaban a cabo tradicionalmente las relaciones internacionales. Principios clásicos como la soberanía, conceptos indiscutidos como el de independencia, ideas claras y distintas como la de nacionalidad, fueron afectadas en sus bases y debieron comenzar, lentamente, a reformular su significado real.

La diversificación geográfica de los medios de producción, el desarrollo de los nacionalismos basados en la idea de independencia económica, y la formación de grupos o alianzas de nacionaes de carácter económico, han desintegrado en parte la unidad y armonia clásica del concepto jurídico de nacionalidad, nacido para representar normativamente a las relaciones planteadas entre sujetos inequívocamente pertenecientes a Estados Naciones que, por otra parte, actuaban como protagonistas únicos y exclusivos de las relaciones internacionales.

\section{El concepto de empresa}

Uno de los fenómenos del proceso de cambio señalado, el movimiento de concentración y expansión internacional de la industria, ha contribuido a provocar también la ruptura del concepto original de empresa. La transformación de los primitivos talleres en fábricas, de las fábricas en corporaciones nacionales y de éstas en corporaciones multidivisionales, algunas de las cuales se convierten en multinacionales (5), ha eliminado la antigua unidad económico-juridico-administra-

5. Véase el tratamiento de las relaciones entre crecimiento de la empresa, división interna del trabajo y estructuras organizativas, en Stephen Hymer, Empresas multinacionalcs, Buenos Aires, 1973, cap. II. 
tiva, por la cual un agrupamiento de personas se organizaba en sociedad (estructura juridica) para explorar una empresa (estructura económica) que poseía una planta o establecimiento (estructura técnica o administrativa).

En la economía actual, una planta puede producir varias mercaderias, actuando en diversos mercados; pero también una sociedad puede controlar diversas plantas, y una sociedad puede controlar otras sociedades, o lo que es igual, una empresa puede manifestarse en cierto número de personas jurídicas ligadas entre si por relaciones de propiedad, de administración o meramente contractuales (6).

En otras palabras, las unidades económicas han perdido su individualidad, a causa de la comunidad de bienes e intereses que se produce al establecerse sobre las mismas una misma estructura de poder o control. El resultado de este proceso se manifiesta en diversas formas de concentración de empresas: absorción o fusión de unas unidades por otras, creación de nuevas unidades por varias otras, descentralización de las unidades existentes.

El análisis de este fenómeno, especialmente en una de sus dimensiones - la concentración por descentralización internacional de las unidades productivaspermite destacar una distinción crucial: la que separa los conceptos de empresa y sociedad.

Hoy en día está más o menos claro que el concepto de empresa se refiere a los centros de decisión económica y administración patrimonial que reúnen un conjunto de recursos productivos afectados a una misma actividad o fin económico.

El concepto de sociedad, en cambio, se refiere a una de las técnicas disponibles (sin duda, la más imporiante) para la expresión o manifestación jurídica de las empresas, para dotarlas de una organización interna y para impulsar su crecimiento (7). Precisamente, la técnica societaria - y especialmente la de la sociedad anónima- es la que ha favorecido, junto a

6. Ver Eduardo White, El derecho de la concentración de cmpresas y los procesos de concentración económica, Revista Derecho de la Integración No 6, Buenos Aires, 1970.

7. Véase la elaboración de esta distinción en los trabajos de Jean Paillusseau, La Société anonyme, technique dorganisation de l'entreprise, París 1967, y C. Champaud, Le pouvoir de concentration de la société par actions, París, 1962. otros factores, el proceso de internacionalización de la producción a que hacemos referencia. Gracias al principio según el cual una sociedad puede ser socia de otra, dondequiera se encuentren ambas localizadas, un mismo centro de decisión económica puede actualmente expresarse, a través de distintas combinaciones de participaciones accionarias, en numerosas entidades dotadas cada una de personalidad jurídica, limitación de responsabilidades y órganos propios de administración, y sometidas a diferentes ordenamientos jurídicos nacionales (8). Gracias a este principio, la empresa Ford es, sin perder su unidad, alrededor de 60 sociedades distintas, cuarenta de las cuales tienen sede fuera de Estados Unidos; Philips existe en 66 países que le han otorgado independientemente personalidad moral; y la I.T.T. es un conglomerado de más de 150 sociedades localizadas en distintos paises del mundo.

La distinción entre empresa y sociedad es crucial para comprender plenamente el alcance teórico y práctico de la noción de nacionalidad y reconocer la existencia de las dos dimensiones básicas en las que puede considerarse y aplicarse como concepto juridico.

\section{Nacionalidad de las sociedades}

La primera dimensión de! concepto de nacionalidad se refiere al estatuto legal de las personas morales, y constituye el vínculo que las une con un ordenamiento juridico determinado, que les otorga capacidad como sujetos de derecho, y define las reglas de su constitución, organización interna, funcionamiento y disolución (9).

Una sociedad, pues, es nacional del país que regula su estatuto juridico. Desde este punto de vista, una empresa tendrá tantas nacionalidades como paises (ordenamientos jurídicos) en los que haya constituido sociedades.

Ahora bien, dado que lo que está en juego en esta dimensión de la nacionalidad es la existencia (jurídica) misma de la empresa, o sea su capacidad como sujeto de derecho y las reglas de su organización y funcionamiento, la identificación del "país de nacio-

8. Véase H. Angelo, Multinaiional corporate enterprises, Academia de La Haya, Cursos, 1968, III, p. 449.

9. Véase Y. Loussouarn y J. Breclin, Droit du commerce international, Paris, 1969, pp. 261-88, y J. Calon, La societé internationale, en Joumal de droit iniernational, 1961, p. 694 y ss. 
nalidad" se efectúa con base en indicadores que satisfagan requisitos de unidad, seguridad e igualdad (10). Como es sabido, en el derecho positivo comparado se encuentran dos criterios para determinar la nacionalidad de las sociedades: el de la "incorporación", según el cual las sociedades son nacionales del país donde se han constituido, y el de la sede, que se refiere ai país donde se encuentra la organización social, sus órganos de administración o el asiento principal de sus negocios. Ambos criterios, con algunas diferencias, satisfacen los requisitos mencionados. En primer lugar, los indicadores empleados son de naturaleza jurídico-formal: si bien esto es más evidente en el criterio del lugar de constitución, también es cierto en el caso de la sede, aun si lo que se busca es la sede real, pues no se trata de identificar la sede económica sino la sede juridica, es decir, normalmente, la de los órganos de la sociedad. Bajo las dos formas, entonces, se garantiza la seguridad, la certidumbre del estatuto legal. En segundo lugar, este último permanece siempre idéntico a sí mismo: una misma sociedad no puede tener sino una sola nacionalidad, es decir, un solo estatuto; y los casos de doble estatuto son resueltos, en principio, por el derecho internacional privado. En tercer lugar, los criterios empleados permiten asignar o negar nacionalidad a las sociedades en forma igualitaria, es decir, no discriminatoria en términos internacionales: los requisitos son válidos para todas las empresas, capitales y socios, cualquiera sea su procedencia.

A los efectos de este análisis, nos interesa señalar que esta acepción del concepto de nacionalidad permite clasificar a las sociedades en la forma siguiente:

\section{A. Sociedades nacionales o extranjeras}

Las sociedades se distinguen en nacionales $y$ extranjeras según que, de acuerdo a los criterios elegidos por los paises para determinar al ordenamiento jurídico que rige su constitución, organización, funcionamiento y disolución, dicho ordenamiento juridico sea nacional o extranjero.

\section{B. Sociedades internacionales}

Las sociedades son internacionales en la medida en que sea el orden jurídico internacional el que les

10. Véase Eduardo White, El tema de la nacionalidad de las empresas en la perspectiva de las relaciones económicas internacionales, en Revista del Derecho Comercial y de las Obligaciones, Buenos Aires, 1973. otorgue personeria juridica, y fije sus condiciones de organización y funcionamiento. Esta hipótesis puede verificarse a través de un tratado o convenio internacional, o mediante decisiones de un organismo internacional con competencia para ello.

Los antecedentes más importante de esta figura se encuentran en la experiencia europea, especialmente dentro de los programas de integración económica. Al respecto, deben señalarse: i) el régimen de empresas comunes del EURATOM, previsto en los artículos 45 a 51 del Tratado de Roma (11); ii) el proyecto de Estatuto de la Sociedad Anónima Europea, elaborado por la Comisión de las Comunidades y todavía no sancionada (12); iii) las Ilamadas "corporaciones públicas multinacionales", establecidas por los Estados europeos luego de la Segunda Guerra Mundial para realizar trabajos, servicios públicos y finalmente actividades comerciales e industriales conjuntas, y entre cuyos ejemplos más conocidos se encuentran EUROFIMA, EUROCHEMIC, SAARLOR, Scandinavian Airlines System (SAS), etc. (13).

En América Latina, probablemente los únicos casos de "sociedad internacional" sean los de la Corporación Centroamericana de Servicios de Navegación Aérea (COCESNA), y la empresa binacional ITAIPU, creada por el Tratado entre Brasil y Paraguay para el aprovechamiento hidroeléctrico del río Paraná.

El Régimen Uniforme de Empresas Multinacionales establecido por la decisión 46 del Grupo Andino otorga algunos elementos de internacionalidad al estatuto juridico de las sociedades sujetas al mismo. Sin embargo, como hemos destacado en otro trabajo (14) la empresa multinacional Andina no puede ser considerada "sociedad internacional" pues su personería juridica no es concedida por un organismo subregional, que-

11. Véase A. Sereni, La imprese comuni dell'EURATOM, en Rivista di diritto Intemazionale, vol. XVIII, 1960 , p. 213, y E. Libbrecht, "Les caracteres essencieles des entrcprises communes de l'EURATOM". en Revue Trimestrelle de Droit Européen, num. 4, julio-diciembre, 1971 , pp. 623-4.

12. Véase Diario Oficial de la CEE, 1970, C 124/1, y E. Cerexce, la sociedad Europea, en Revista Derecho de la Integración, $\mathrm{N}^{\circ}$ 9, Buenos Aires, 1971.

13. Véase H. T. Adam, Les organismes internationaux specialisés, París, 1965, y C. Fliger, Multinational Public Enterprises, Washington, 1969.

14. Véase E. White, Empresas multinacionales latinoamericanas, op. cit., pág. 93 y 55. 
dando tanto sli otorgamiento como su extinción en manos de las autoridades nacionales.

\section{Sociedades multinacionales}

En las sociedades multinacionales, un doble o múltiple estatuto jurídico es previsto deliberadamente como ley aplicable, es decir, se estipula la aplicación simultánea de dos o más leyes nacionales a una misma sociedad. La complicada situación a que puede dar lugar este sistema (comprensible exclusivamente en los casos en que los socios de cada país desean conservar las vinculaciones nacionales de una empresa común hasta sus últimas consecuencias) explica la escasa utilización que ha tenido hasta el momento.

Suelen mencionarse dos ejemplos de "sociedades multinacionales": el de la Compañía Universal del Canal de Suez, sometida simultáneamente a la ley francesa y la egipcia, y el de Air-Afrique, que de acuerdo a su tratado constitutivo tiene la nacionalidad de "cada uno de los Estados Contratantes" (once paises africanos (15).

\section{Nacionalidad de las empresas}

La segunda dimensión del concepto de nacionalidad se refiere al goce de determinados derechos y a la imposición de obligaciones específicas a los centros de decisión económica (empresas), en función del grado o del tipo de su vinculación con uno o varios sistemas económicos nacionales.

El objetivo de las reglas que utilizan la noción de nacionalidad en este sentido es casi siempre la promoción o bien la restricción de las actividades de dichos centros de decisión, y no su organización y funcionamiento jurídico-formales. No obstante, dado que la técnica societaria es la principal expresión jurídica de las empresas, la individualización de las mismas, a los efectos de la imputación de los derechos y obligaciones respectivos, se ejerce a través y por medio de la persona moral. Lo que interesa, sin embargo, no es esta última sino la realidad económica subyacente.

En realidad, si puede discutirse (terminológicamente) que el vínculo que determina la ley aplicable o

15. Véase B. Goldman, "Le droit des societés internationales", en Journal du Droit International, 1963, p. 320 . el ordenamiento juridico a que pertenecen las sociedades, sea de nacionalidad, también podría sostenerse que el mismo término no parece del todo adecuado para presentar el vínculo que señala los derechos y obligaciones específicas a que está sujeta una empresa por su relación con la economía nacional (16). En ambos casos, seria más lógico quizás hablar de pertenencia, de subordinación: de orden estrictamente jurídico en el primer caso, que representa un problema de derecho internacional privado; y de orden más bien político en el segundo, que cae en la esfera del $\mathrm{De}$ recho Público. Pero mientras no se encuentre un término más apropiado, el concepto de nacionalidad parece suficientemente amplio y flexible para evocar a estas relaciones.

La digresión anterior sirve para destacar un punto crucial en el problema de la nacionalidad y sus diferentes dimensiones: en efecto, entre los vínculos que pueden establecerse entre una persona - física o moral- y el Estado. hay algunos que representan una relación más estrecha que la que surge de la simple calidad de sujeto del orden jurídico interno.

La determinación de la nacionalidad de las empresas se efectúa normalmente mediante la aplicación de distintas variantes de la "teoria del control", nacida en Europa durante la Primera Guerra Mundial, para permitir el secuestro de los bienes de las compañias controladas por extranjeros enemigos, y comenzada a aplicar en América Latina al declararse el estado de be-

16. La confusión que todavía reina en esta materia puede advertirse, por ejemplo, en la doctrina argentina, que desde hace tiempo viene polarizándose entre quienes afirman $y$ quienes niegan la nacionalidad, sin advertir que en lo sustancial, se trata de una guerra de palabras. El círculo vicioso deriva, en nuestra opinión, de la rigidez juridicista con que se enfoca el problema, oponiéndose los puntos de vista del derecho público a los del derecho privado, y la nacionalidad de las personas jurídicas a la de las personas físicas. En muy pocos casos se tiene en cuenta la distinción básica entre empresa y sociedad. Véase C. J. Zavala Rodríguez, $\mathrm{Na}$ cionalidad de las sociedades, en $\mathrm{El}$ Derecho, t-6, p. 1047; Isaac Halperin, Sociedades Comerciales, p. 125, E. Aztiria, La nacionalidad de las sociedades mercantiles en la Academia Interamericana, 1948; F. Polak, En torno al régimen de las sociedades constituidas en el extranjero, en Revista del Derecho Comercial, $N^{9} 13$, 1970. 
ligerancia contra los países del Eje (17). La teoría del control se refiere a "la influencia preponderante en la orientación general de los negocios", resolviéndose en una noción puramente empírica, compuesta por factores de orden económico, social, psicológico y jurídico que se presentan en general como indicadores de la localización del "centro de decisiones" de la empresa (18).

Referida a la determinación de la nacionalidad de las empresas (19) la teoria del control emplea para ello indicadores como los siguientes:

1. Nacionalidad (o residencia) de los accionistas.

2. Nacionalidad (o residencia) de los admnistradores.

3. Nacionalidad (o residencia) de los empleados.

4. Lugar principal de los negocios.

5. Lugar principal de la investigación tecnológica.

6. Origen principal de los insumos utilizados.

7. Monto de los dividendos remitidos a accionistas extranjeros.

8. Monto de las regalías, intereses, etc., remitidos al exterior.

9. Efectos de sustitución de importaciones y/o expansión de las exportaciones.

10. Control externo mediante contratos de gestión, distribución, exclusividad con empresas establecidas en otros paises.

Como puede verse en esta lista, la determinación de nacionalidad incluye no solamente elementos referidos a la estructura interna de la empresa (los so-

17. Véase C. De Visscher, La protection diplomatique des personnes morales, en Academia de La Haya, Cursos, 1966 , p. 427 y ss.

18. Véase Champaud, op. cit., p. 105 y ss. y Pailleauseau, op. cit., p. 248.

19. La teoría del control ha comenzado a invadir sistemáticamente otras áreas tradicionalmente neutrales del derecho comercial, a través de las modernas legislaciones sobre grupos de sociedades. Los ejemplos más elaborados pertenecen al derecho europeo, y en especial al derecho alemán y francés, aunque en América Latina ya son varias las leyes que la aplican, como las de Argentina, Colombia y Chile. En materia impositiva, de promoción industrial, y por supuesto en materia de inversiones extranjeras, la aplicación de la teoría del control en los países latinoamericanos ya es bastante amplia. Véase INTAL, aspectos jurídicos de la asociación internacional de empresas en América Latina, mimeo, 1973. cios, los administradores, el lugar de explotación) sino también factores y modalidades de su comportamiento externo, como la política de investigaciones tecnológicas y de remesas de beneficios al exterior, cuya captación o representación por las normas jurídicas es extremadamente difícil si se tiene en cuenta el carácter dinámico y cambiante que tienen en la realidad dichas operaciones.

Pero es importante observar también que en algunos de estos casos, la nacionalidad aparece referida, más que al control en sentido estricto, al interés nacional de las empresas, en el sentido de la adecuación de su estructura y/o su comportamiento a una definición dada de ese interés nacional. Ahora bien: en un sistema de planificación económica que establezca diferentes prioridades, ese interés nacional puede variar de acuerdo a las diferentes políticas económicas conque se vinculen las empresas, y en especial, de acuerdo a los diferentes métodos de asignación de los recursos nacionales a los que pueden aspirar aquéllas. Por lo tanto, una misma empresa puede tener distintas "nacionalidades" (es decir, puede ser considerada nacional o extranjera) según se trate, por ejemplo, de acceder a determinado sector de actividad, o solicitar créditos, $u$ obtener beneficios de fomento industrial, o disponer de divisas para pagar regalías a empresas del exterior, o recibir exenciones impositivas, o solicitar protección diplomática al gobierno local, etc. (20) Para cada uno de estos actos, el Estado puede plantear diferentes requerimientos de vinculación con la economía nacional en función de las distintas políticas, y teniendo en cuenta que dichos requisitos de estructura o comportamiento de las empresas no son simplemente simbólicos sino que tienen efectos concretos sobre el sistema económico.

En todos estos casos, los requisitos de seguridad, unidad e igualdad que aparecian en la primera dimensión del concepto de nacionalidad, aparecen relegados por la necesidad de representar y regular la realidad económica y sus cambios. Pero la diferencia se comprende, en principio, si se tiene en cuenta que la atribución de nacionalidad no determina aquí la existencia jurídica misma de las empresas sino, exclusivamente, la medida en que podrán gozar o deberán soportar determinados derechos y determinadas obliga-

20. Véase J. Calon, op. cit., p. 696, Loussouarn y Bredin, op. cit., p. 227 y ss. 
ciones que no hacen a su subsistencia, al menos en términos jurídicos (21).

Sobre la base de las anteriores consideraciones, las empresas pueden ser clasificadas, según el criterio de nacionalidad, en la siguiente forma:

\section{A. Empresas nacionales o extranjeras}

Las empresas se ubicarán en una u otra categoría en la medida en que alguna disposición legal nacional establezca un tratamiento discriminatorio entre las mismas, basado en su grado o tipo de vinculación con la economia nacional, y referido a derechos $y$ obligaciones específicas (22).

En América Latina, casi todos los países hacen uso de la distinción entre empresas nacionales y extranjeras a efectos de reservar a las primeras determinados derechos y beneficios.

El tratamiento discriminatoriio más sistemático se establece en el Régimen Común de Inversiones extranjeras del Grupo Andino, que califica a las empresas nacionales de modo uniforme en los países miembros (empleando el indicador de un porcentaje del capital corregido por la exigencia del "control efectivo" de las decisiones) y les reserva ventajas exclusivas, en materia de acceso a sectores, aprovechamiento de ventajas arancelarias, obtención de crédito interno, etc. (23)

Las legislaciones de Argentina y México, y en menor grado la de Brasil, también aplican la teoría del control para discriminar el tratamiento a las empresas. Es interesante destacar la multiplicidad y fluidez de los criterios elegidos por estos países para determinar la nacionalidad y para vincularla con distintos derechos y obligaciones (incentivos de fomento industrial,

21. Véase Y. Loussouairn y J. Bredin, op. cit.. p. $227 \mathrm{y}$ ss.

22. Teóricamente, caben tres actitudes distintas frente a las empresas extranjeras: absoluta igualdad (tratamiento nacional); reciprocidad, y discriminación sistemítica. La primera consiste, en la práctica, en eliminar la aplicación de la teoría del control, empleando exclusivamente las reglas neutrales del derecho societario, y eliminando, por lo tanto, las distinciones de nacionajidad referidas a las empresas, como tales. Ia reciprocidad, en cambio, es una variante de la técnica discriminatoria.

23. Véase M. Guerrero, El Régimen Común de Inversiones Extranjeras del Grupo Andino, en Revista Derecho de la Integración $\mathrm{N}^{\circ}$ 10, Buenos Aires, 1972. financiamiento, acceso al mercado de capitales, autorizaciones para operar, etc.). Dicha diversidad de criterios refleja las diferentes exigencias de "lealtad" o "identidad nacional" que los legisladores de cada país (y aun los legisladores de un mismo país) imponen a las empresas para gozar de los beneficios o eximirse de las restricciones resultantes de las distintas políticas económicas vigentes en cada materia, sector, región, etc. (24)

\section{B. Empresas multinacionales}

(i) En primer lugar, las empresas serán (juridicamente) multinacionales, sin en razón de su vinculación efectiva con dos o más economias nacionales, y por el interés público multinacional de dicha vinculación, les son atribuidos derechos, privilegios y obligaciones que emanan del orden jurídico internacional.

Así definidas, las empresas multinacionales se ubican sobre todo en la perspectiva de los procesos de integración y cooperación económica entre Estados.

En las áreas de integración económica, la idea de empresa multinacional está vinculada estrechamente con el efecto de ampliación de mercados que es buscado por los gobiernos mediante las medidas de lioeración del intercambio y de armonización de las políticas económicas: el mercado ampliado conduciría a un aumento correlativo en la dimensión de las empresas nacionales, a fin de aprovechar el nuevo espacio económico. Las empresas extenderían así su radio de acción geográfico, multiplicando sus contactos comerciales y sus establecimientos en otros paises; además, la intensificación de la competencia, o bien la planificación conjunta, llevaría al agrupamiento de los productores de un mismo sector en cada pais, creándose asi complejos empresarios de dimensión regional.

Desde un punto de vista menos global, estas empresas son vistas también como mecanismos apropiados para llevar a cabo en forma conjunta proyectos o actividades de utilidad común a dos o más países, en distintos sectores de la economía.

Las empresas multinacionales serian de esta manera instrumentos de ciertos objetivos de los esquemas

24. Véase INTAL, Estudio de los aspectos juridicos de la asociación internacional de empresas en América Latina, op. cit., p. 125 y ss. 
y procesos de cooperación e integración: 1) impulsarian las interrelaciones comerciales, financieras y tecnológicas entre los países, creando una interdependencia real entre sus economías e impulsando la coordinación de sus políticas, 2) permitirian encarar actividades económicas para las cuales no serian suficientes los recursos de cada país empleados aisladamente, 3) cumplirían función de salvaguardia de la autonomía de decisión nacional frente a la fuerza competitiva de las corporaciones internacionales de los países más industrializados, y 4) contribuirían a lograr el desarrollo equilibrado de los países, o en otras palabras, serian instrumentos de la distribución equitativa de los beneficios del proceso de convergencia de las economias nacionales.

En este sentido, la calificación de una empresa como multinacional dependerá de una decisión política de los Estados interesados, que estará basada, en principio, en los siguientes elementos:

- la realización de una actividad económica en común por empresas pertenecientes a dos o más Estados, o la realización de una actividad económica por empresas de un Estado de manera que comprenda o afecte el sistema económico de dos o más Estados;

-la existencia de un interés público internacional en la realización de determinada actividad, es decir, un interés común a dos o más Estados, cuya satisfacción exige determinado nivel de cooperación entre los mismos;

-la necesidad de atribuir determinados privilegios o ventajas a la o las empresas, en razón del carácter internacional de las operaciones a realizar, o debido a dificultades, económicas o legales, que surgen de la actividad en cuestión;

-El objetivo de mantener cierto grado de control sobre la actividad de las empresas, como contrapartida de las ventajas otorgadas, y a fin de garantizar el cumplimiento de los propósitos asignados a las mismas.

Es importante señalar que la estructura multinacional de la propiedad de estas empresas no es un requisito conceptualmente necesario para su calificación de multinacionales. Pese a que en algunos esquemas de promoción de este tipo de empresas, y particularmente en América Latina, se incluye dicho requisito en el modelo de empresa tenido en cuenta, los factores decisivos para identificar a las empresas multi- nacionales son, teóricamente, fundamentalmente dos: la calificación de su pertenencia regional (determinada normalmente por alguna variante de la teoría del control) y la definición de sus objetivos dentro de un programa o proyecto de interés multinacional.

Dada la necesidad de asegurar los rasgos y finalidades que se les asignan, estas empresas aparecerán generalmente asociadas a un contexto institucional (que tendrá también, de algún modo, carácter multinacional).

En casi todos los sistemas de integración económica existen esquemas institucionales vinculados a la promoción de este tipo de empresas (25). En la Comunidad Económica Europea, el caso más típico es el de las "empresas comunes" del EURATOM, ya mencionado, aunque deben tenerse en cuenta también otros mecanismos empleados por los gobiernos, como los programas internacionales de producción integrada realizados en el marco de la OTAN (26) o propuestos por las autoridades comunitarias, como el Grupo de Interés Económico aplicado a escala europea, los Contratos Comunitarios de desarrollo Industrial, etc. (27)

Las "empresas de finalidad común" (joint purpose enierprises) de la Organización de Cooperación Regional para el desarrollo (Irán, Paquistán y Turquia) (28), las industrias de Africa del Este (29), las "empresas comunes" del COMECON (30), son otras tantas experiencias, algunas frustradas y otras exitosas, dirigidas a los mismos objetivos.

En América Latina, la parcialmente fracasada experiencia de las Industrias Centroamericanas de Integración, y el todavia no aplicado sistema del Grupo Andino para la creación y funcionamiento de empresas multinacionales andinas, son los principales antecedentes de este tipo.

25. Estos esquemas están estudiados comparativamente en E. White, Empresas multinacionales latinoamericanas, op. cit., cap. III.

26. Véase M. D'Auriac y otros, Organisation de programmes internationales de Production Integrée. Lieja, 1936.

27. Véase CEE, La politique Industrielle de la Communauté, Bruselas, 1970.

28. Véase M. Brewster, Industrial Integration Schemes, UNCTAD, TD/B/345, 1971.

29. Véase P. Robson, Economic Integration in Africa, Londres, 1968.

30. Véase J. Caillot, Le C.A.E.M., París, 1971. 
El marco jurídico de este tipo de empresas multinacionales será establecido a través de un tratado o convenio internacional, o mediante la decisión de un organismo internacional competente. Pero en estos casos el orden jurídico internacional no se ocupa necesariamente del estatuto juridico, de las condiciones de organización y funcionamiento, como en el caso de las "sociedades internacionales", sino de la atribución de determinados derechos o privilegios a la empresa (libre movilidad de capitales, eliminación de la doble imposición, facilidades de crédito en todos los paises) con el objeto de facilitarle coordinadamente su actividad multinacional. La multinacionalidad jurídica de la empresa aparece referida, pues, a su actividad económica, aunque su estructura organizativa, su perscnalidad moral, continúe dependiendo de un orden jurifidico nacional.

(ii) Desde otro punto de vista, también puede aceptarse que una empresa será juridicamente multinacional, aun no dependiendo del orden jurídico internacional, cuando determinadas disposiciones legales de un pais establezcan que su estructura $\mathrm{y} / \mathrm{o}$ funcionamiento debe ser multinacional, a los efectos de gozar de ciertos beneficios y someterse a ciertas obligaciones, que pueden ser distintos a los que se conceden a las empresas calificadas como nacionales o extranjeras (31). En estos casos, pues, las empresas son obligatoriamente multinacionales: puede tratarse de la integración multinacional del capital o de los órganos de dirección, de la realización de actividades o fijación de sedes en varios países, etc. La diferencia entre estas empresas y las reguladas con intervención del derecho internacional reside en el sometimiento de las primeras a la voluntad del legislador nacional, que en última instancia puede decidir, unilateralmente, la modificación del marco jurídico especial (por ejemplo, con incentivos especiales) que se les hubiere asignado especialmente.

Pueden citarse diversos casos que podrían ubicarse dentro de esta segunda categoría jurídica de empresa multinacional. En Europa existen varios ejemplos de asociación de empresas de diferentes paises, con la intervención directa o los respectivos gobiernos, pero sin recurrir a normas internacionales. Uno de los más conocidos es el de FIAT-CITROEN, en el que el gobierno francés fijó claramente la estructura multinacio-

31. Véase B. Goldman. Le droit des societées internationales, en J. de Droit International, 1963. p. 320. nal del capital del "holding" común que se estableció para controlar a CITROEN. También se han venido registrando interesantes experiencias de asociación en el campo bancario, del material de transporte, de la electrónica, etc., en todas las cuales se ha pretendido asegurar la multinacionalidad juridica y económica de los proyectos (32).

En América Latina, deben señalarse, entre otros casos de este tipo, a la empresa Monómeros ColomboVenezolanos, controlada por compañias colombianas y venezolanas, a la Flota Mercante Gran Colombiana, a la Corporación Centroamericana de Servicios de Navegación Aérea, a la compañia Altos Hornos de Centroamérica, y algunos otros proyectos comunes entre empresas de distintos países en los que, aunque en

- forma menos elaborada, es posible detectar elementos multinacionales no solamente en la estructura económica sino también en su ordenamiento jurídico particular (33).

Por último, cabría preguntarse hasta qué punto la figura juridica de "empresa mixta" establecida por los países del Grupo Andino para calificar a las firmas en las que participa el capital extrazonal hasta un $49 \%$ del capital social, no configura una categoría autónoma de empresa multinacional, en la medida en que es sujeta a un estatuto legal diferente, con derechos y obligaciones distintas, al que se aplica a las empresas calificadas como nacionales y extranjeras.

\section{Empresas transnacionales}

Desde el punto de vista jurídico, empresas transnacionales serian aquéllas que, en razón de la dimensión de sus operaciones internacionales, medida por el número de países en que actúan, la importancia de los negocios y de los sectores en que operan, etc. (34), son sometidas por un acuerdo internacional, o por normas comunes sancionadas por los paises, a

32. Véanse algunos de estos casos en C. Layton, Cross Frontier Mergers in Europe, Bath, 1970.

33. Véase INTAL, op. cit., p. 243 y sig.

34. Existen muy diversas definiciones económicas de las empresas transnacionales, o corporaciones multinacionales, o firmas extraterritoriales, o empresas internacionales, o corporaciones globales, etc., según el punto de vista de cada observador. Véase la lista de definiciones que presenta el informe de Naciones Unidas, op. cit., p. 118 y ss. 
ciertas reglas únicas o uniformes para controlar su comportamiento en las distintas economías nacionales.

Esta figura todavía no ha sobrepasado el plano de la expresión de deseos, de la discusión de propuestas, especialmente en el ámbito de los organismos internacionales, lo que se explica teniendo en cuenta el objetivo a alcanzar: se trataría de encuadrar jurídicamente a los grandes conglomerados internacionales, de codificar la estructura y el comportamiento de los grandes oligopolios industriales y comerciales, de los cuales ya depende el $20 \%$ del Producto Bruio del mundo entero (excluidos los países socialistas). Se tataría, en todo caso, de encontrar una respuesta adecuada a un fenómeno cada vez más evidente: las grandes empresas transnacionales han comenzado a convertirse en instrumentos autónomos para la regulación del comercio y la inversión internacional: gran parte de lo que los paises denominan comercio exterior o inversión extranjera es en realidad comercio interno $y$ descentralización de la producción que se realizan en el marco de un mismo centro de decisión económica (35). Paralelamente, el poder económico de las empresas multinacionales, que en muchos casos sobrepasa al de numerosos miembros de las Naciones Unidas, les confiere un significativo poder político, una especial capacidad de intervención, directa o indirecta, en asuntos internos de los paises, que éstos perciben como pérdida de soberania y dependencia (36).

Desde el punto de vista jurídico, los problemas a resolver para remontar esta situación son graves. Una empresa transnacional es un conjunto de sociedades actuando simultáneamente en varios paises, bajo distintas leyes y jurisdicciones, pero unidas por un lazo vertical de control entre una sociedad matriz y diversas sociedades filiales, que asegura su adecuación a una estrategia global común. La base de estas entidades está, pues, fraccionada en tantas partes como países en los que se establezcan. Su estructura or-

35. Véase Comisión Arancelaria de Estados Unidos, Las corporaciones multinacionales: sus efectos sobre el comercio y la inversión mundiales y sobre el comercio exterior y el trabajo estadounidenses, en Boletín Mensual del CEMLA, 1973, No 3 y sig.

36. Véase los trabajos de Vernon, Evans, Wells y otros en R. Kehoane y Joseph Nye, Transnactional relations and World politics, Harvard, 1972 y E. White, Democracia piuralista y empresas muitinacionales, en Revista Criterio, Buenos Aires, 1972 . ganizativa, los actos de transferencia de recursos de un país a otro, los impuestos que deben pagar, los sectores en que pueden operar, están sometidos a las reglas que sanciona cada Estado nacional, dándose lugar así a un verdadero laberinto jurídico (37).

En realidad, las grandes corporaciones internacionales desenvuelven lo substancial de su actividad en una especie de "tierra de nadie" jurídica: sencillamente, no calzan en los casilleros legales diseñados por los países. A pesar de ello, pero en buena medida también gracias a ello, estas empresas han podido desarrollar métodos de planificación global de los negocios, que les permiten utilizar y controlar recursos situados en diversas partes del mundo, por encima de las jurisdicciones a que los mismos pertenecen utilizar y controlar recursos situados en diversas partes del mlindo, por encima de las jurisdicciones a que los mismos perlenecen formalmente. En esta forma, se ha venido creando un incipiente ordenamiento jurídico "paralelo" en el campo del comercio y de la producción internacional, cuya principal fuente es la práctica de las empresas transnacionales: los acuerdos entre empresas organizadas oligopólicamente constituyen verdaderos tralados internacionales que reparten los mercados, asignan tipos y volúmenes de producción a los países, fijan los precios de las exportaciones; los sistemas de precios internos entre firmas de un mismo grupo permiten sancionar en la práctica, el nivel de los aranceles aduaneros, los tipos de cambio eiectivos, las tasas impositivas realmente aplicadas (38). El derecho de los contratos internacionales en muchas materias es de hecho "legislado" por la empresa transnacional sobre la base de contratos de adhesión; los convenios de "concesión" que realizan con algunos gobiernos, por ejemplo para la explotación de recursos naiurales, no tienen mayor diferencia con los acuerdos celebrados entre Estados Soberanos; y hasta un nuevo mercado de capitales como el de los Eurobonos,

37. Véase Detlev Vagts, The global corporation and International Law, en The Journal of International Law and Economics, 249 (1972), Jack Behrman, The multinational enterprise, its initiatives and governmental reactions, en The Journal of International Law and Economics 217 (1972).

38. Véase C. Vaitzos, Income distribution, Wefore considerations and transnational enterprises, mimeo, Lima 1972. 
ha sido creado y desarrollado por la actividad de las corporaciones internacionales, en parte como respuesta a los controles de los paises de origen de las empresas sobre la exportación de capitales (39).

Por esta vía, la legislación económica de los países corre el peligro de una especie de "vaciamiento", cuyas causas principales residen en la multiplicidad de aliernativas que poseen las empresas y en la incapacidad de los Estados Nacionales para encontrar su respuesta en otras alternativas.

Hasta el momento, la intervención del derecho internacional en este campo es muy escasa. Aparte de los compromisos asumidos dentro de esquemas de integración regional, como los de la Comunidad Económica Europea (que no se refieren, en principio, a esta perspectiva de la empresa multinacional), los principales ejemplos de derecho positivo se refieren a los llamados "Tratados de Amistad, Comercio y Navegación" (40) y a los convenios de garantía de las inversiones, en maieria de convertibilidad, expropiación, guerra o riesgos de diverso tipo (41).

Existen, además, varios principios clásicos de derecho internacional público vinculados con la actividad empresaria internacional -la protección diplomática, la responsabilidad del Estado, los límites territoriales al ejercicio de la jurisdicción legislativa o judicial, la inmunidad de la soberanía - surgidos de la costumbre o de la doctrina internacionales, pero cuya aplicabilidad depende de la interpretación que de ellos hagan los tribunales, como parte del derecho nacional respectivo. Un caso de la falta de firmeza que todavía presenta el derecho internacional en esta materia es la discusión permanente acerca de la existencia y alcance de una pauta internacional para el tratamiento de las empresas extranjeras, especialmente en el campo de la propiedad (por ejemplo, la definición de in-

39. Véase H. Angelo, op. cit.

40. Estos acuerdos, generalmente bilaterales, son típicos de la segunda posgnerra mundial y sus cláusulas - cle dudosa efectividad- se refieren a la obligación recíproca de otorgar tratamiento nacional o de más favor a los nacionales de cada Estado.

41. Véase Z. Kronfol, Protection of foreign investment, Lciden, 1972, pp. 58-80, E. Nwogugu, The legal problems of foreign investment in developing countries, Manchester, 1965, y R. Lillich, The protection of foreign invesiment, New York, 1965. demnización justa y adecuada) y de la discriminación de derechos y obligaciones (42).

Es probable que la estrategia más realista para el control de los grandes conglomerados consista en un tratamiento por etapas y por distintos niveles de tratamiento.

En términos generales, la elaboración de dicha estrategia debería incluir la participación de los gobiernos de los países que pueden ser calificados como receptores de las empresas transnacionales, la de los gobiernos de los países de origen, y en alguna medida, también la de las propias empresas.

Por otro lado, los frentes de acción deberían distinguir entre aquellas materias que pueden encararse a nivel regional y aquellas que exigen una aproximación internacional, como también entre la adopción de reglas a instituciones comunes y la armonización de las politicas nacionales.

Para los países en desarrollo, un modelo de estrategia regional ya se ha puesto en marcha con el Régimen Común de Inversiones Extranjeras del Grupo Andino. Si bien ciertos aspectos de este esquema están basados en la previa adopción de un programa de integración económica, algunos de sus principales mecanismos pueden adaptarse también a la coordinación de políticas entre paises que, aunque no participen de un mismo esquema de desarrollo conjunto, desean igualar el tratamiento a las inversiones extranjeras sobre la base de algunas pautas comunes, especialmente en maieria de incentivos y de requisitos de participación local.

Sin embargo, las estrategias regionales (salvo, quizás, en la medida en que pudiera coordinarse entre todos los grupos de países ubicados en una situación similar frente a las empresas transnacionales, como serian los países en desarrollo, que todavía expresan estrategias muy dispares) no alcanzarian para dominar y poner a su servicio el factor crucial en el poder

42. En años recientes se han realizado algunas tentativas en esta materia, a través de nuevos mecanismos internacionales, como las convenciones de la OECD (1967) y del Banco Mundial (1965) en materia de solución de conflictos entre gobiernos nacionales y "nacionales de otros Estados". La jurisdicción atribuida a los tribunales en ellos establecidos debe ser previamente reconocida por los Estados. Véase G. Schwarzenberger, Foreign Investment and International Law, Londres 1969. 
de las empresas, es decir, su capacidad de planificación global y de movilización de recursos sobre la base de una pluralidad de alternativas dispersas en el mundo.

En ese sentido parecen dirigirse algunas de las propuestas que actualmente se están debatiendo en foros iniernacionales, y especialmente en las Naciones Unidas (43). Entre las líneas de acción posibles, se destaca la armonización en materia tributaria, dirigida a obtener una distribución más justa de los beneficios de las empresas, entre éstas y los distintos países en los que actúan, y también a controlar el problema de la transferencia de precios entre las unidades de una misma firma que comercian de un país a otro. Otro campo de acción importante es el de las prácticas restrictivas de comercio (44), para los cuales no sería realista pensar en una agencia antitrust internacional, pero sí, en cambio, en alguna institución que

13. Véase Naciones Unidas, op. cit., p. 75.

44. Véase UNCTAD, Prácticas comerciales restrictivas, TD/122/Supp. 1, Enero 1972. sirviera como agencia de un "acuerdo general sobre corporaciones multinacionales", en la línea del GATT, y dotada de ciertos poderes de investigación y recomendación (45).

Por último, debería adelantarse la consideración de un Centro de Información Internacional sobre las empresas transnacionales, que permitiera recoger, sistematizar y proporcionar información sobre los movimientos internacionales de recursos controlados por las empresas, su distribución geográfica, precios, etc. y el impacto de las estrategias empresarias en las políticas y legislaciones nacionales. Más allá de las eventuales dificultades politicas para llevar a cabo un proyecto de este tipo, debe reconocerse que su realización sería crucial para permitir la aplicación a las empresas transnacionales de las técnicas del derecho económico, viables únicamente en la medida en que reflejen el conocimiento integral de la realidad que pretenden regular.

45. P. Goldberg y Ch. Kindleberger, Toward a Gatt for investment, en Law and Policy in international business, 1970. 